\title{
MicroRNA-335 is downregulated in bladder cancer and inhibits cell growth, migration and invasion via targeting ROCK1
}

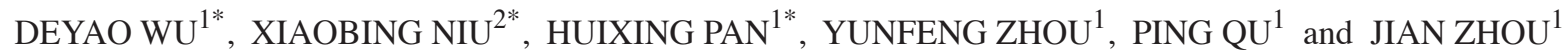 \\ ${ }^{1}$ Department of Urology, The Fourth Affiliated Hospital of Nantong Medical College, Yancheng, Jiangsu 224001; \\ ${ }^{2}$ Department of Urology, Huai'an First People's Hospital, Nanjing Medical University, \\ Huai'an, Jiangsu 223300, P.R. China
}

Received May 4, 2015; Accepted February 1, 2016

DOI: $10.3892 / \mathrm{mmr} .2016 .5055$

\begin{abstract}
The expression of microRNA-335 (miR-335) has been demonstrated to be downregulated in numerous types of cancer. Thus far, no previous studies have investigated the miR-335 expression in bladder cancer. In the present study, the expression and effects of miR-335 were assessed in bladder cancer. The results of the present study provided, to the best of our knowledge, the first evidence that miR-335 is downregulated in the tumor tissue of patients with bladder cancer. Following transfection of miR-335, MTT, cell migration and invasion, luciferase and western blot assays were conducted in bladder cancer cell lines. The results demonstrated that miR-335 inhibited cell proliferation, migration and invasion in T24 and EJ cells. In addition, the results suggested that miR-335 directly targets Rho-associated protein kinase 1 (ROCK1) in bladder cancer. The present study provided a novel therapeutic target, the miR-335/ROCK1 axis in bladder cancer. The suggested approach will be beneficial in developing an effective treatment against bladder cancer.
\end{abstract}

\section{Introduction}

Bladder cancer is the second most common malignant tumor in the urogenital tract in the USA, and the seventh most common cancer worldwide (1). In the USA, there was an estimated 72,500 newly diagnosed cancer cases and 17,960 cases of cancer-associated mortality in 2013 (2). The most common type of bladder cancer is comprised of transitional cell carcinoma that arises from transitional epithelium (3). Bladder

Correspondence to: Professor Jian Zhou or Professor Ping Qu, Department of Urology, The Fourth Affiliated Hospital of Nantong Medical College, 15 Yuehe Road, Yancheng, Jiangsu 224001, P.R. China

E-mail: luqiang0405@163.com

E-mail: ping_qu1967@163.com

*Contributed equally

Key words: bladder cancer, ROCK1, miR-335 cancer is classified as having either non-muscle-invasive or muscle-invasive tumors. Upon initial diagnosis, $\sim 75 \%$ cases are classified as non-muscle-invasive and $\sim 25 \%$ of cases as muscle-invasive (4). Patients with non-muscle-invasive bladder cancer have a high rate of recurrence, and in certain cases become muscle-invasive (5). Despite the development of various surgical and chemotherapeutic methods for the treatment of bladder cancer, it remains a highly prevalent and lethal malignancy (1). Therefore, there is a requirement for sensitive and reliable biomarkers, therapeutic targets and approaches for the treatment of bladder cancer.

Previous studies have demonstrated that microRNAs (miRNAs) are expressed in numerous types of human cancer (6-8). miRNAs are a class of small non-coding RNAs whose mature products are 17-27 nucleotides long (9). miRNAs negatively regulate protein expression by inducing degradation or impairing the translation of target mRNAs, by specifically binding to the 3 prime untranslated region (3'-UTR) of target mRNAs $(10,11)$. Although the biological functions of the miRNAs are unknown, previous studies demonstrated that they serve a role as regulators, involved in all hallmarks of cancer (12-14). miRNAs may regulate diverse biological processes, including cell proliferation, development, differentiation, apoptosis and tumorigenesis of cancer (9). Increasing evidence has indicated that deregulation of miRNAs may function as either a tumor suppressor or an oncogene in the tumorigenesis of numerous types of human cancer (7). Thus, identifying the targets of the miRNAs is important to understand their function in cancer development and progression, as miRNAs may be a target for cancer therapy.

Previous studies demonstrated that the expression of miR-335 is downregulated in multiple tumor types (15-18). However, miR-335 expression remains to be investigated in bladder cancer. The current study demonstrated that miR-335 was downregulated in tumor tissues from human bladder cancer compared with their normal adjacent tissues (NATs). Furthermore, results demonstrated that miR-335 inhibited cell proliferation, migration and invasion by directly targeting Rho-associated protein kinase 1 (ROCK1). The data of the present study have diagnostic and therapeutic implications, and may be exploited for the development of further treatment strategies in bladder cancer. 


\section{Materials and methods}

Clinical specimens. Bladder cancer and adjacent normal tissues (27 samples) were obtained from patients diagnosed histopathologically with bladder cancer and who had received radical cystectomy at The Fourth Affiliated Hospital of Nantong Medical College (Yancheng, China), between 2008 and 2012. None of the patients had received other therapies, such as chemotherapy and radiotherapy, prior to radical cystectomy. All samples were immediately placed in liquid nitrogen following excision from patients, and were subsequently frozen at $-80^{\circ} \mathrm{C}$ for RNA extraction. The present study was approved by the Hospital's Protection of Human Subjects Committee, and informed consent was obtained from all patients. The clinicopathological features of the patients are summarized in Table I.

$R N A$ isolation, reverse transcription-quantitative polymerase chain reaction ( $R T-q P C R)$. Total RNA was extracted from tissues using TRIzol reagent (Invitrogen; Thermo Fisher Scientific, Inc., Waltham, MA, USA) according to the manufacturer's instructions, and RT reactions were performed using the M-MLV Reverse Transcriptase system (Promega Corporation, Madison, WI, USA). RT-qPCR was performed using a standard protocol from the SYBR Green PCR kit (Toyobo Co., Ltd., Osaka, Japan). Each sample was analyzed in triplicate. The primer sequences used were as follows: miR-335, F 5'-TCAAGAGCAATAACGAAAAATGT-3' and R 5'-GCTGTCAACGATACGCTACGT-3'; and U6, F 5'-CGC TTCGGCAGCACATATAC-3' and R 5'-TTCACGAATTTG CGTGTCAT-3'. Data were normalized using the endogenous U6 snRNA and fold changes were calculated using the $2^{-\triangle \Delta C q}$ normalization method with the following formula: $\Delta \Delta \mathrm{C}_{\mathrm{q}}=\mathrm{C}_{\mathrm{q}}$ miR-335-C $\mathrm{C}_{\mathrm{q}} \mathrm{U6}$ (19).

Cell culture. The bladder cancer cell lines, T24 and EJ, were purchased from the Institute of Biochemistry and Cell Biology (Shanghai, China). Cells were maintained in Roswell Park Memorial Institute-1640 medium supplemented with $10 \%$ fetal bovine serum (FBS) and 1\% penicillin/streptomycin (Gibco; Thermo Fisher Scientific, Inc.), and incubated at $37^{\circ} \mathrm{C}$ in a humidified atmosphere with $5 \% \mathrm{CO}_{2}$.

Cell transfection. Mature miR-335 mimics and miRNA negative control mimics (NC) were obtained from Shanghai GenePharma Co., Ltd. (Shanghai, China). For functional analysis, T24 and EJ cells were seeded into 6-well plates $24 \mathrm{~h}$ prior to transfection to ensure $60-70 \%$ confluency at the time of transfection. Cells were transfected with miR-335 mimics or NC using Lipofectamine 2000 (Invitrogen; Thermo Fisher Scientific, Inc.) according to the manufacturer's instructions.

Cell proliferation assay. Human bladder cancer cells were seeded into 96-well plates in triplicate at a density of $3 \times 10^{3}$ cells/well, $24 \mathrm{~h}$ subsequent to transfection with miR-335 or NC mimics. Cell proliferation was assessed using the 3-(4,5-dimethylthiazol-2-yl)-2,5-diphenyltetrazolium bromide (MTT) assay at various time points subsequent to transfection. Briefly, MTT solution $(5 \mathrm{mg} / \mathrm{ml}$; Sigma-Aldrich, St. Louis, MO, USA) was added to each well and incubated at $37^{\circ} \mathrm{C}$ for $4 \mathrm{~h}$. The MTT solution was then discarded and $200 \mu 1$ dimethyl sulfoxide was added to the cells to dissolve the formazan crystals precipitated. Absorbance was measured at a wavelength of $490 \mathrm{~nm}$ using an enzyme-linked immunosorbent assay reader (Elx800; Bio-Rad Laboratories, Inc., Hercules, CA, USA). All experiments were performed in triplicate. The suppression rate was calculated using the following formula: Suppression rate $=[1$-optical density (OD) miR-335/ODmiR-NC] x $100 \%$.

Cell migration and invasion assay. Corning Costar transwell chambers (Thermo Fisher Scientific, Inc.) with $8 \mu \mathrm{m}$ pore size polycarbonate membrane were used to assess cell migration and invasion. For the invasion assay, the membrane was pre-coated with Matrigel (BD Biosciences, San Jose, CA, USA). Transfected cells $\left(5 \times 10^{4}\right)$ were seeded on the upper chamber with serum-free medium. A volume of $0.5 \mathrm{ml}$ of $20 \%$ FBS-containing medium was added to the lower chamber as a chemoattractant. Cells were then incubated for another $12 \mathrm{~h}$ for the migration assay and $24 \mathrm{~h}$ for the invasion assay. The membranes were stained with $0.1 \%$ crystal violet (Beyotime Institute of Biotechnology, Haimen, China), and five visual fields of x 200 magnification of each membrane were randomly selected for cell counting under an inverted CKX41 microscope (Olympus Corporation, Tokyo, Japan).

Western blot analysis. Subsequent to a 72-h transfection with miR-335 or NC mimics, human bladder cancer cells were lysed in ice-cold radioimmunoprecipitation assay lysis buffer containing $1 \mathrm{mM}$ phenylmethylsulfonyl fluoride (Beyotime Institute of Biotechnology). Lysates were centrifuged at $12,000 \mathrm{x} \mathrm{g}$ for $40 \mathrm{~min}$ at $4^{\circ} \mathrm{C}$, and the protein sample was diluted, heated for denaturation, and then subjected to $10 \%$ sodium dodecyl sulfate-polyacrylamide gel electrophoresis for $20 \mathrm{~min}$ at $70 \mathrm{~V}$ and transferred to a polyvinylidene difluoride membrane (EMD Millipore, Billerica, MA, USA) for $70 \mathrm{~min}$ at $110 \mathrm{~V}$. Membranes were then incubated with rabbit anti-human polyclonal anti-ROCK1 (cat no. 4035S; 1:1,000) or anti- $\beta$-actin (cat no. 4970L 1:1,000; Cell Signaling Technology, Inc., Danvers, MA, USA) primary antibodies overnight. Membranes were rinsed in Tris-buffered saline containing $0.05 \%$ Tween 20 (Beyotime Institute of Biotechnology) three times, and then incubated for $2 \mathrm{~h}$ with the corresponding goat anti-rabbit horseradish peroxidase conjugated secondary antibody (sc-2054; 1:10,000; Santa Cruz Biotechnology, Inc., Dallas, TX, USA). Proteins were visualized with an ECL kit (Pierce Biotechnology, Inc., Rockford, IL, USA) and analyzed using Quantity One 1-D analysis software (version 4.62; Bio-Rad Laboratories, Inc.).

Luciferase assay. Human bladder cancer cells were seeded into a 12 -well plate at $\sim 90 \%$ confluency and transfected with the reporter plasmid, miR-335 or NC mimics. The Renilla and firefly luciferase activity were measured $48 \mathrm{~h}$ subsequent to transfection with the Dual-Luciferase Reporter Assay System (Promega Corporation) and a luminometer (Infinite 200 PRO NanoQuant; Tecan Group Ltd., Männedorf, Switzerland). The firefly luciferase activity was normalized to the renilla luciferase activity for each transfected well. All experiments were performed in triplicate. 
Table I. Summary of clinicopathological features of bladder cancer.

\begin{tabular}{|c|c|c|c|c|}
\hline Patient No. & Sex & Age & Grade & Stage \\
\hline 1 & M & 61 & 2 & T2N0M0 \\
\hline 2 & $\mathrm{~F}$ & 59 & 1 & T2N0M0 \\
\hline 3 & M & 55 & 1 & T2N0M0 \\
\hline 4 & $\mathrm{M}$ & 55 & 3 & T1N0M0 \\
\hline 5 & M & 65 & 2 & T1N0M0 \\
\hline 6 & M & 45 & 3 & T4N0M0 \\
\hline 7 & M & 58 & 1 & T4N0M0 \\
\hline 8 & $\mathrm{~F}$ & 62 & 2 & T2bN0M0 \\
\hline 9 & M & 62 & 3 & T2N0M0 \\
\hline 10 & M & 77 & 2 & T2N0M0 \\
\hline 11 & M & 82 & 3 & T1N0M0 \\
\hline 12 & $\mathrm{~F}$ & 69 & 2 & T2bN0M0 \\
\hline 13 & M & 82 & 1 & T4N0M0 \\
\hline 14 & M & 76 & 3 & T1N0M0 \\
\hline 15 & $\mathrm{M}$ & 77 & 2 & T1N0M0 \\
\hline 16 & $\mathrm{M}$ & 68 & 2 & T4N2M0 \\
\hline 17 & $\mathrm{M}$ & 81 & 1 & T2N0M0 \\
\hline 18 & $\mathrm{M}$ & 73 & 1 & T1N0M0 \\
\hline 19 & $\mathrm{M}$ & 66 & 2 & T1N0M0 \\
\hline 20 & M & 68 & 3 & T3bN0M0 \\
\hline 21 & M & 77 & 1 & TaNOM0 \\
\hline 22 & M & 52 & 3 & T1N0M0 \\
\hline 23 & M & 43 & 2 & T1N0M0 \\
\hline 24 & $\mathrm{M}$ & 67 & 2 & T1N0M0 \\
\hline 25 & M & 61 & 1 & T1N0M0 \\
\hline 26 & $\mathrm{M}$ & 53 & 3 & T3aNOM0 \\
\hline 27 & $\mathrm{~F}$ & 64 & 2 & TaNOMO \\
\hline
\end{tabular}

M, male; F, female.

Statistical analysis. Data are presented as the mean \pm standard deviation, and were analyzed using SPSS software, version 13.0 (SPSS, Inc., Chicago, IL, USA). Data were analyzed using the Chi-square test. Kaplan-Meier curves were constructed, and the log-rank test was performed for analysis of survival data. $\mathrm{P}<0.05$ was considered to indicate a statistically significant difference.

\section{Results}

miR-335 expression in bladder cancer tissues and association with clinicopathological factors. A total of 27 bladder cancer samples were included in the present study. As demonstrated in Fig. 1, miR-335 was significantly downregulated in bladder cancer tissues compared with the NAT $(\mathrm{P}<0.01)$. These results suggested that miR-335 may serve an important role in human bladder cancer.

miR-335 suppressed cell proliferation in the T24 and EJ cells. the MTT assay was conducted to investigate whether miR-335 has a biological function in cell proliferation. As demonstrated
A

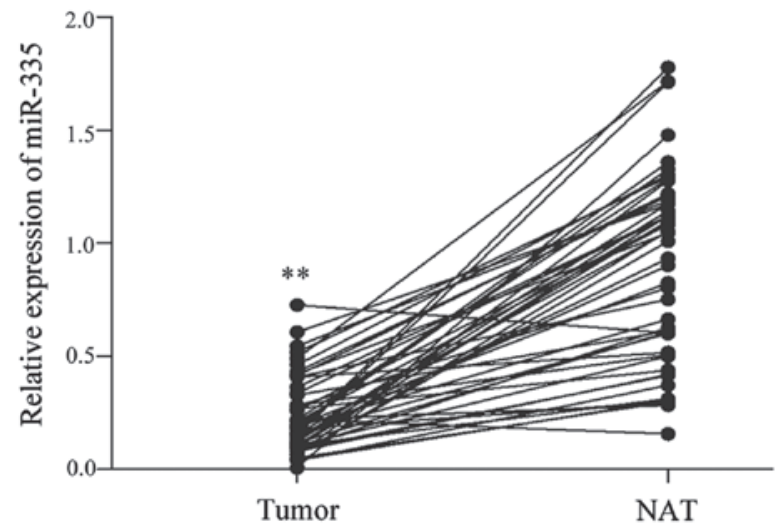

B

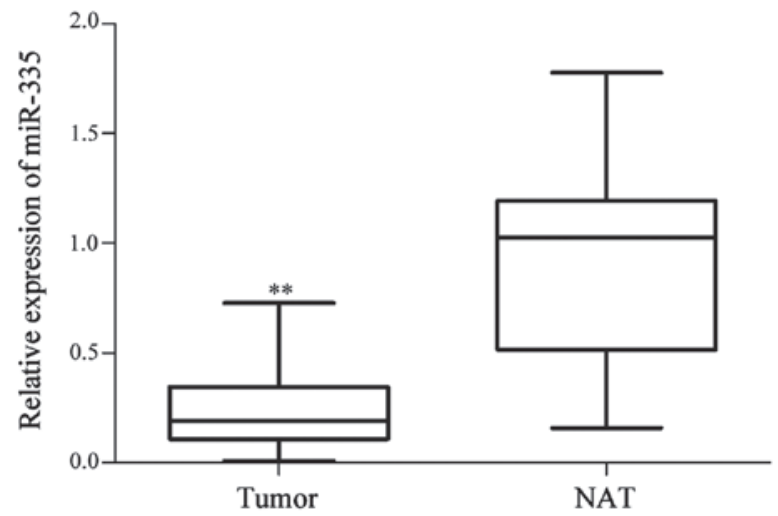

Figure 1. (A) Expression patterns of miR-335 in urinary bladder cancer tissues. The miR-335 levels were determined in 27 surgical specimens of human bladder cancer tissues and NATs. (B) Reverse transcription-quantitative polymerase chain reaction analysis indicated a statistically significant suppression of miR-335 expression in bladder cancer tumor tissues compared with NATs. ${ }^{* *} \mathrm{P}<0.01$ vs. negative control. miR-335, microRNA-335; NAT, normal adjacent tissue.

in Fig. 2, upregulation of miR-335 markedly inhibited cell proliferation compared with the NC. The results indicated that after a 120-h treatment, the suppression rate of miR-335 reached $38.98 \pm 4.5 \%$ in T24 cells and $24.97 \pm 4.9 \%$ in EJ cells ( $\mathrm{P}<0.05$; Fig. 2).

miR-335 suppressed cell migration and invasion in the T24 and EJ cells. Taking the fact that T24 and EJ cells are metastatic cells into consideration, it was investigated whether a reduction in miR-335 had an effect on the capacities of cells to migrate and invade. As demonstrated in Fig. 3, the migratory and invasive capacities of T24 and EJ cells transfected with miR-335 were markedly reduced compared with the NC. These results indicated that miR-335 reduced cell migration and invasion in the bladder cancer cells.

ROCK1 is a direct target gene of miR-335 in the T24 and EJ cells. To identify the target gene of miR-335, a public database (TargetScan; http://www.targetscan.org) was used, and ROCK1 was predicted to be a target of miR-335 (Fig. 4A). To verify whether miR-335 directly targeted ROCK1, luciferase reporter assays were performed. As 

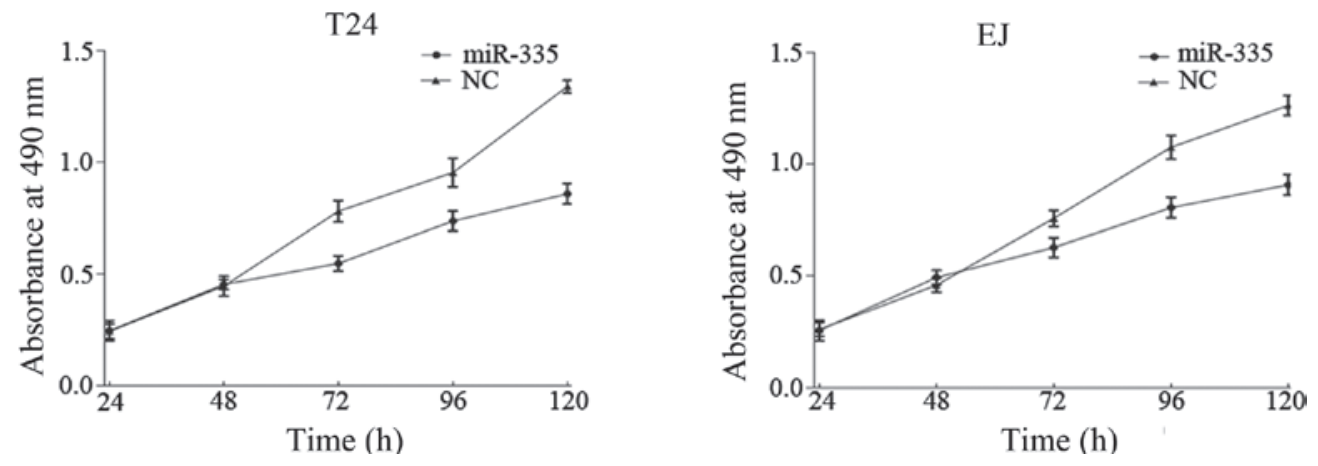

Figure 2. Cell proliferation was determined by the 3-(4,5-dimethylthiazol-2-yl)-2,5-diphenyltetrazolium bromide assay. Upregulation of miR-335 significantly suppressed cell proliferation in T24 and EJ cells. miR-335, microRNA-335; NC, negative control.

\section{$\mathrm{T} 24$}

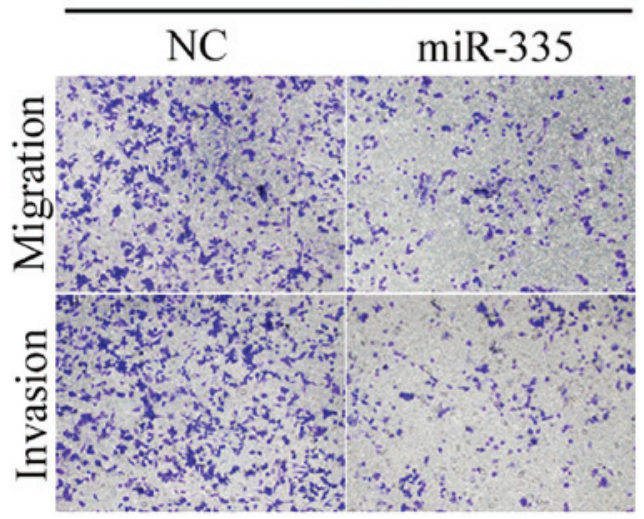

EJ

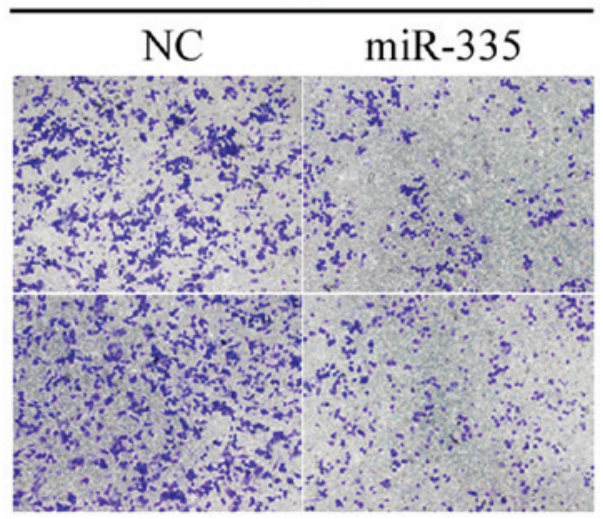

Figure 3. Forced expression of miR-335 suppressed cell migration and invasion in the Transwell assay. T24 and EJ cells were transfected with NC or miR-335 mimics. Cells were then incubated for $12 \mathrm{~h}$ for the migration assay and $24 \mathrm{~h}$ for the invasion assay. NC, negative control; miR-335, microRNA-335.

demonstrated in Fig. 4B, miR-335 significantly inhibited the wild type, and not the mutated luciferase activity of ROCK1 in the T24 and EJ cells $(\mathrm{P}<0.05)$. Furthermore, western blot analysis was conducted to investigate whether ROCK1 protein expression levels were reduced following transfection of miR-335 in the T24 and EJ cells. As demonstrated in Fig. 4C, ROCK1 protein expression levels were significantly downregulated following transfection of miR-335 $(\mathrm{P}<0.05)$. The results indicated that ROCK1 is a direct target gene of miR-335 in the bladder cancer T24 and EJ cells.

\section{Discussion}

The aberrant expression of miRNAs in bladder cancer has been investigated previously (20). Certain miRNAs were indicated to be upregulated in bladder cancer tissues and may function as tumor oncogenes by negatively regulating tumor suppressors (21). miRNAs are small, stable, easy to deliver and be detected, thus, their abnormal expression may certify them as potential biomarkers and novel targets for bladder cancer therapy (22). However, further studies are required to address the potential diagnostic and therapeutic roles of these miRNAs in bladder cancer, and whether this may be beneficial for the treatment of bladder cancer.

Aberrant expression of miR-335 has been demonstrated in numerous types of tumor, suggesting a complex role during tumorigenesis. Previous studies have demonstrated that it is downregulated in osteosarcoma (15), gastric cancer (16), small cell lung cancer (17), breast cancer (18), ovarian cancer (23), clear cell renal cell carcinoma (24), hepatocellular carcinoma (25) and prostate cancer (26). Furthermore, upregulation of miR-335 has been demonstrated in colorectal cancer (27), glioma (28) and myeloma (29). However, the expression, function and mechanism of miR-335 in human bladder cancer remains to be elucidated. The present study demonstrated that miR-335 was downregulated in human bladder cancer tissues compared with NATs, suggesting that miR-335 may have a tumor suppressive role in bladder cancer development and progression.

Identification of the miR-335 target genes is important for understanding its role in tumorigenesis, and defining novel therapeutic targets. Thus far, dishevelled associated activator of morphogenesis $1(30)$, paired box $6(31,32)$, ROCK1 (15), retinoblastoma 1 (33), zinc finger E-box binding homeobox 2 (34), met proto-oncogene (35) and OCT4 (36) have been identified as targets of miR-335. The current study demonstrated that miR-335 transfection resulted in reduced cell proliferation, migration and invasion in bladder cancer T24 and EJ cells by targeting ROCK1. These results are in agreement with previous studies in human osteosarcoma (15). The results of the present study suggested that miR-335 may be used for the development of novel molecular markers and 
A

Position 472-478 of ROCK1 13' UTR 5' ...GACUUAAGUUUUUGUGCUCUUGC.

hsa-miR-335

3. UguaAaAagcaAuAaCGAGAACU

B
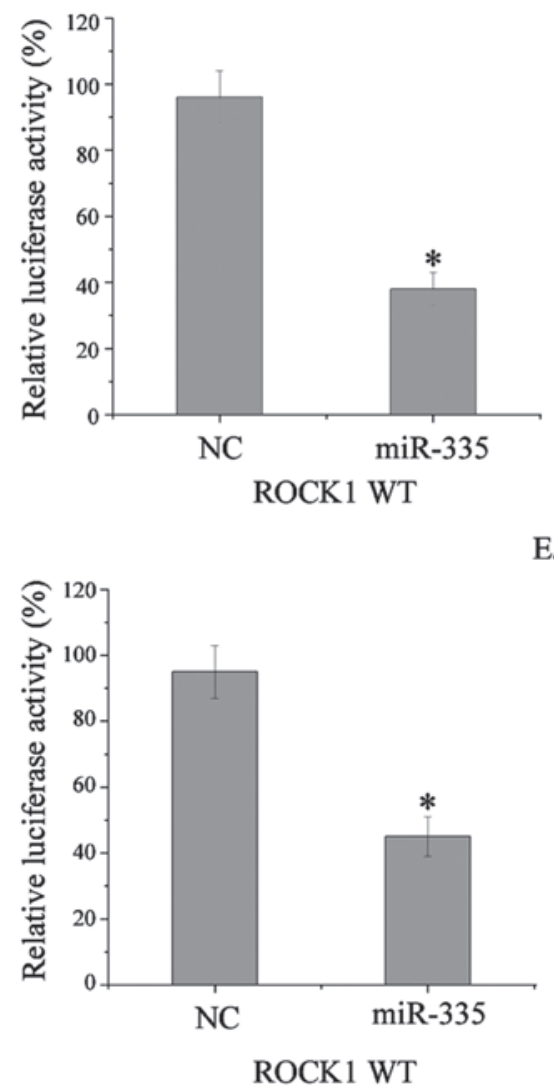

C
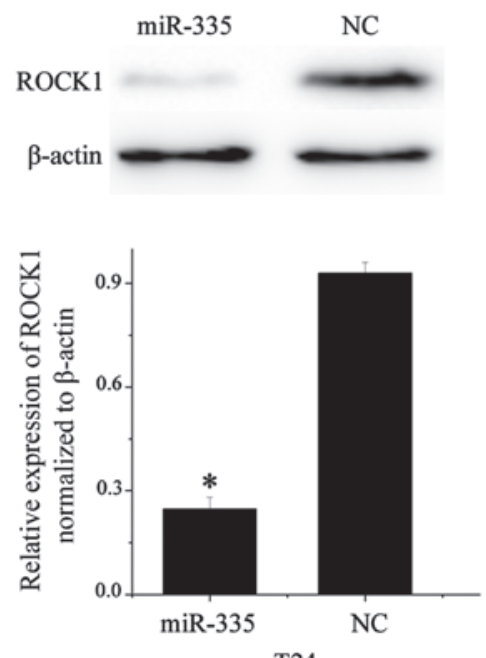

$\mathrm{T} 24$
EJ

$\mathrm{T} 24$
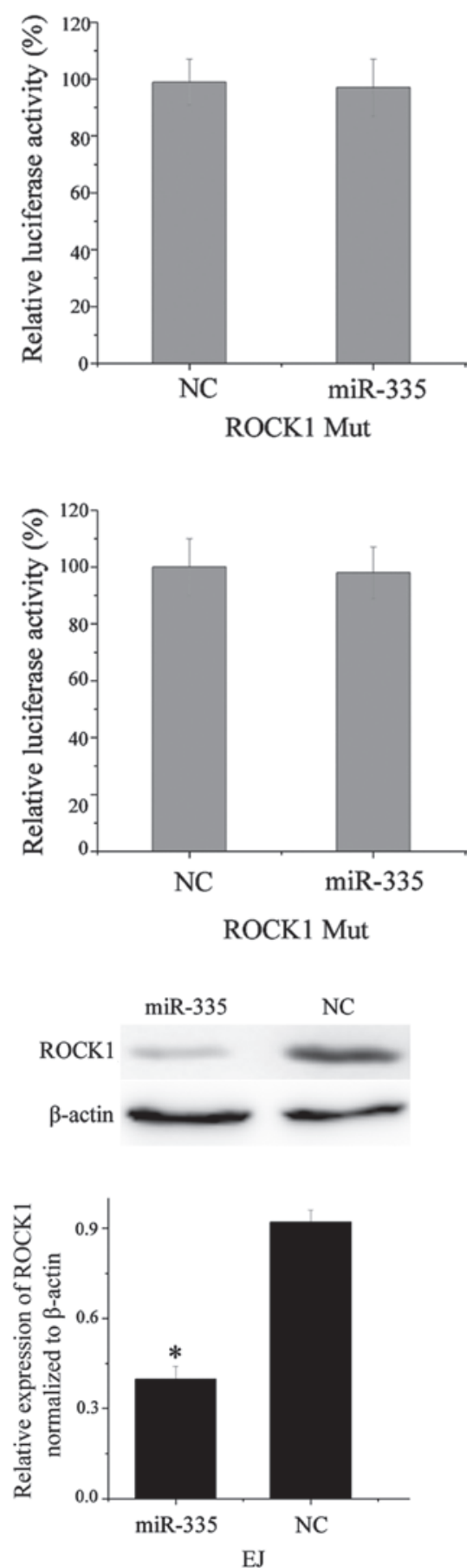

Figure 4. (A) Targetscan assessment indicated that ROCK1 mRNA contained a miR-335 seven-nucleotide seed match at position $472-478$ of the ROCK1 3'-UTR. (B) ROCK1 may be a direct target of miR-335 in vitro. Overexpression of miR-335 significantly inhibited the WT, however not the Mut, luciferase activity of ROCK1 in T24 and EJ cells. "P<0.05 vs. NC. (C) Downregulation of ROCK1 was confirmed by western blotting, following transfection, $\beta$-actin was used as the control. " $\mathrm{P}<0.05$ vs. NC. 3'-UTR, 3 prime untranslated region; hsa-miR-335, human microRNA-335; NC, negative control; ROCK1, rho-associated protein kinase 1; WT, wild type; Mut, mutated.

therapeutic approaches to inhibit the metastasis of bladder cancer.

The Rho guanosine triphosphate (GTP)ase family consists of small proteins that bind to and hydrolyze GTP, and control a wide variety of cellular processes, such as cell motility, proliferation, adhesion, differentiation and apoptosis (37). ROCK is one of the best characterized Rho effectors (38). The two ROCK isoforms, ROCK1 and ROCK2, share 65\% identity in amino-acid sequence and $92 \%$ identity in their kinase domains, and display certain similarities in the kinase activity 
domain (39). Upregulation of ROCK promotes invasion and metastasis in numerous solid tumors, such as bladder (40), hepatocellular (41), breast (42) and colon cancers (43). In addition, overexpression of ROCK1 has been associated with the progression of bladder cancer (40). This is consistent with the results of the present study which demonstrated that exogenetic overexpression of miR-335 inhibited the migration and invasion of human bladder cancer cells. These observations provide the evidence that miR-335 has an effect on cell migration and invasion via regulating the expression of ROCK1.

Human ROCK1 maps to chromosome 18 (18q11.1) (44). Previous studies demonstrated that ROCK1 functioned as an oncogene and was regulated by a number of miRNAs in human cancer. An et al (45) and Xu et al (46) demonstrated that miR-124 inhibited cell migration and invasion via directly targeting ROCK1 in bladdercancer and glioma. In gastric cancer, miR-148a suppressed cell metastasis by downregulating the expression of ROCK1 (47). ROCK1 was also targeted in other types of human cancer, including miR-335 in neuroblastoma (48), miR-584 in renal cell carcinoma (49) and miR-146a in prostate cancer (50). The current study demonstrated that miR-335 inhibited bladder cancer cell proliferation and motility by downregulation of ROCK1. This may be further investigated as a predictive value for early detection of tumor recurrence and target therapy drugs to prevent bladder cancer from becoming invasive.

In conclusion, to the best of our knowledge, this is the first study to demonstrate that miR-335 is downregulated in bladder cancer. The current study provided evidence that miR-335 suppressed cell proliferation, migration and invasion by directly targeting ROCK1 in bladder cancer. Identifying the candidate target genes of miR-335 may provide an understanding of potential carcinogenic mechanisms in bladder cancer. These observations indicated that miR-335 may serve an important role as a diagnostic and prognostic marker in bladder cancer, and may be exploited for further treatment of bladder cancer.

Further research is required to identify the full potential of miR-335 in cancer treatment, and its benefits in the treatment of bladder cancer.

\section{References}

1. Hendricksen K and Witjes JA: Current strategies for first and second line intravesical therapy for nonmuscle invasive bladder cancer. Curr Opin Urol 17: 352-357, 2007.

2. Siegel R, Naishadham D and Jemal A: Cancer statistics, 2013. CA Cancer J Clin 63: 11-30, 2013.

3. Pasin E, Josephson DY, Mitra AP, Cote RJ and Stein JP: Superficial bladder cancer: an update on etiology, molecular development, classification, and natural history. Rev Urol 10: 31-43, 2008.

4. Babjuk M, Oosterlinck W, Sylvester R, Kaasinen E, Bohle A, Palou-Redorta J, Roupret M and European Association of Urology: EAU guidelines on non-muscle-invasive urothelial carcinoma of the bladder, the 2011 update. Eur Urol 59: 997-1008, 2011.

5. Luke C, Tracey E, Stapleton A and Roder D: Exploring contrary trends in bladder cancer incidence, mortality and survival: implications for research and cancer control. Intern Med J 40 357-362, 2010.

6. Esquela-Kerscher A and Slack FJ: Oncomirs-microRNAs with a role in cancer. Nat Rev Cancer 6: 259-269, 2006.

7. Wu D, Zhou Y, Pan H, Zhou J, Fan Y and Qu P: microRNA-99a inhibiting cell proliferation, migration and invasion by targeting fibroblast growth factor receptor 3 in bladder cancer. Oncol Lett 7: 1219-1224, 2014
8. Zheng K, Liu W, Liu Y, Jiang C and Qian Q: MicroRNA-133a suppresses colorectal cancer cell invasion by targeting Fascin1. Oncol Lett 9: 869-874, 2015.

9. Liu LY, Wang W, Zhao LY, Guo B, Yang J, Zhao XG, Hou N, Ni L, Wang AY, Song TS et al: Mir-126 inhibits growth of SGC-7901 cells by synergistically targeting the oncogenes PI3KR 2 and Crk, and the tumor suppressor PLK2. Int J Oncol 45: 1257-1265, 2014.

10. Guancial EA, Bellmunt J, Yeh S, Rosenberg JE and Berman DM: The evolving understanding of microRNA in bladder cancer. Urol Oncol 32: 41 e31-40, 2014.

11. Yoshino H, Seki N, Itesako T, Chiyomaru T, Nakagawa M and Enokida $\mathrm{H}$ : Aberrant expression of microRNAs in bladder cancer. Nat Rev Urol 10: 396-404, 2013.

12. Croce CM: Causes and consequences of microRNA dysregulation in cancer. Nat Rev Genet 10: 704-714, 2009.

13. Naito Y, Yasuno K, Tagawa H, Sakamoto N, Oue N, Yashiro M, Sentani K, Goto K, Shinmei S, Oo HZ et al: MicroRNA-145 is a potential prognostic factor of scirrhous type gastric cancer. Oncol Rep 32: 1720-1726, 2014

14. Liu Z, Xu Y, Long J, Guo K, Ge C and Du R: microRNA-218 suppresses the proliferation, invasion and promotes apoptosis of pancreatic cancer cells by targeting HMGB1. Chin J Cancer Res 27: 247-257, 2015

15. Wang Y, Zhao W and Fu Q: miR-335 suppresses migration and invasion by targeting ROCK 1 in osteosarcoma cells. Mol Cell Biochem 384: 105-111, 2013.

16. Bae IH, Park MJ, Yoon SH, Kang SW, Lee SS, Choi KM and Um HD: Bcl-w promotes gastric cancer cell invasion by inducing matrix metalloproteinase-2 expression via phosphoinositide 3-kinase, Akt and Sp1. Cancer Res 66: 4991-4995, 2006.

17. Gong M, Ma J, Guillemette R, Zhou M, Yang Y, Yang Y, Hock JM and Yu X: miR-335 inhibits small cell lung cancer bone metastases via IGF-IR and RANKL pathways. Mol Cancer Res 12: 101-110, 2014.

18. Tavazoie SF, Alarcon C, Oskarsson T, Padua D, Wang Q, Bos PD, Gerald WL and Massague J: Endogenous human microRNAs that suppress breast cancer metastasis. Nature 451: $147-152,2008$

19. Chen X, Bo L, Zhao X and Chen Q: MicroRNA-133a inhibits cell proliferation, colony formation ability, migration and invasion by targeting matrix metallopeptidase 9 in hepatocellular carcinoma. Mol Med Rep 11: 3900-3907, 2015.

20. Zabolotneva AA, Zhavoronkov A, Garazha AV, Roumiantsev SA and Buzdin AA: Characteristic patterns of microRNA expression in human bladder cancer. Front Genet 3: 310, 2012.

21. Wu D, Ding J, Wang L, Pan H, Zhou Z, Zhou J and Qu P: microRNA-125b inhibits cell migration and invasion by targeting matrix metallopeptidase 13 in bladder cancer. Oncol Lett 5: 829-834, 2013 .

22. Feng Y, Kang Y, He Y, Liu J, Liang B, Yang P and Yu Z: microRNA-99a acts as a tumor suppressor and is down-regulated in bladder cancer. BMC Urol 14: 50, 2014.

23. Cao J, Cai J, Huang D, Han Q, Yang Q, Li T, Ding H and Wang Z: miR-335 represents an invasion suppressor gene in ovarian cancer by targeting Bcl-w. Oncol Rep 30: 701-706, 2013.

24. White NM, Bao TT, Grigull J, Youssef M, Girgis A, Diamandis M, Fatoohi E, Metias M, Honey JR, Stewart R, et al: miRNA profiling for clear cell renal cell carcinoma: biomarker discovery and identification of potential controls and consequences of miRNA dysregulation. J Urol 186: 1077-1083, 2011.

25. Dohi O, Yasui K, Gen Y, Takada H, Endo M, Tsuji K, Konishi C, Yamada N, Mitsuyoshi H, Yagi N, et al: Epigenetic silencing of miR-335 and its host gene MEST in hepatocellular carcinoma. Int J Oncol 42: 411-418, 2013.

26. Wang L, Alcon A, Yuan H, Ho J, Li QJ and Martins-Green M: Cellular and molecular mechanisms of pomegranate juice-induced anti-metastatic effect on prostate cancer cells. Integr Biol (Camb) 3: 742-754, 2011.

27. Vickers MM, Bar J, Gorn-Hondermann I, Yarom N, Daneshmand M, Hanson JE, Addison CL, Asmis TR, Jonker DJ, Maroun J, et al: Stage-dependent differential expression of microRNAs in colorectal cancer: potential role as markers of metastatic disease. Clin Exp Metastasis 29: 123-132, 2012

28. Shu M, Zhou Y, Zhu W, Zhang H, Wu S, Chen J and Yan G: MicroRNA 335 is required for differentiation of malignant glioma cells induced by activation of cAMP/protein kinase A pathway. Mol Pharmacol 81: 292-298, 2012. 
29. Ronchetti D, Lionetti M, Mosca L, Agnelli L, Andronache A, Fabris S, Deliliers GL and Neri A: An integrative genomic approach reveals coordinated expression of intronic miR-335, miR-342, and miR-561 with deregulated host genes in multiple myeloma. BMC Med Genomics 1: 37, 2008.

30. Shu M, Zheng X, Wu S, Lu H, Leng T, Zhu W, Zhou Y, Ou Y, Lin $\mathrm{X}$, Lin Y, Xu D, et al: Targeting oncogenic miR-335 inhibits growth and invasion of malignant astrocytoma cells. Mol Cancer 10: 59, 2011.

31. Cheng Q, Cao H, Chen Z, Ma Z, Wan X, Peng R and Jiang B: PAX6, a novel target of miR-335, inhibits cell proliferation and invasion in glioma cells. Mol Med Rep 10: 399-404, 2014.

32. Meng Y, Zou Q, Liu T, Cai X, Huang Y and Pan J: microRNA-335 inhibits proliferation, cell-cycle progression, colony formation, and invasion via targeting PAX6 in breast cancer cells. Mol Med Rep 11: 379-385, 2015.

33. Shi L, Jiang D, Sun G, Wan Y, Zhang S, Zeng Y, Pan T and Wang Z: miR-335 promotes cell proliferation by directly targeting Rb1 in meningiomas. J Neurooncol 110: 155-162, 2012.

34. Sun Z, Zhang Z, Liu Z, Qiu B, Liu K and Dong G: MicroRNA-335 inhibits invasion and metastasis of colorectal cancer by targeting ZEB2. Med Oncol 31: 982, 2014.

35. Gao Y, Zeng F, Wu JY, Li HY, Fan JJ, Mai L, Zhang J, Ma DM, Li Y and Song FZ: MiR-335 inhibits migration of breast cancer cells through targeting oncoprotein c-Met. Tumour Biol 36: 2875-2883, 2015.

36. Gao L, Yang Y, Xu H, Liu R, Li D, Hong H, Qin M and Wang Y: MiR-335 functions as a tumor suppressor in pancreatic cancer by targeting OCT4. Tumour Biol 35: 8309-8318, 2014.

37. Etienne-Manneville S and Hall A: Rho GTPases in cell biology. Nature 420: 629-635, 2002.

38. Matsui T, Amano M, Yamamoto T, Chihara K, Nakafuku M, Ito M, Nakano T, Okawa K, Iwamatsu A and Kaibuchi K: Rho-associated kinase, a novel serine/threonine kinase, as a putative target for small GTP binding protein Rho. EMBO J 15: 2208-2216, 1996 .

39. Montalvo J, Spencer C, Hackathorn A, Masterjohn K, Perkins A, Doty C, Arumugam A, Ongusaha PP, Lakshmanaswamy R, Liao JK, et al: ROCK1\&2 perform overlapping and unique roles in angiogenesis and angiosarcoma tumor progression. Curr Mol Med 13: 205-219, 2013.
40. Kamai T, Tsujii T, Arai K, Takagi K, Asami H, Ito Y and Oshima H: Significant association of Rho/ROCK pathway with invasion and metastasis of bladder cancer. Clin Cancer Res 9: 2632-2641, 2003.

41. XueF,Takahara T,Yata Y,Xia Q,Nonome K, ShinnoE,Kanayama M, Takahara S and Sugiyama T: Blockade of Rho/Rho-associated coiled coil-forming kinase signaling can prevent progression of hepatocellular carcinoma in matrix metalloproteinase-dependent manner. Hepatol Res 38: 810-817, 2008

42. Lane J, Martin TA, Watkins G, Mansel RE and Jiang WG: The expression and prognostic value of ROCK I and ROCK II and their role in human breast cancer. Int J Oncol 33: 585-593, 2008.

43. Vishnubhotla R, Sun S, Huq J, Bulic M, Ramesh A, Guzman G, Cho $\mathrm{M}$ and Glover SC: ROCK-II mediates colon cancer invasion via regulation of MMP-2 and MMP-13 at the site of invadopodia as revealed by multiphoton imaging. Lab Invest 87: 1149-1158, 2007.

44. Lock FE, Ryan KR, Poulter NS, Parsons M and Hotchin NA: Differential regulation of adhesion complex turnover by ROCK1 and ROCK2. PLoS One 7: e31423, 2012.

45. An L, Liu Y, Wu A and Guan Y: microRNA-124 inhibits migration and invasion by down-regulating ROCK1 in glioma. PLoS One 8: e69478, 2013

46. Xu X, Li S, Lin Y, Chen H, Hu Z, Mao Y, Xu X, Wu J, Zhu Y, Zheng $\mathrm{X}$, et al: MicroRNA-124-3p inhibits cell migration and invasion in bladder cancer cells by targeting ROCK1. J Transl Med 11: 276, 2013.

47. Zheng B, Liang L, Wang C, Huang S, Cao X, Zha R, Liu L, Jia D, Tian Q, Wu J, et al: MicroRNA-148a suppresses tumor cell invasion and metastasis by downregulating ROCK1 in gastric cancer. Clin Cancer Res 17: 7574-7583, 2011.

48. Lynch J, Fay J, Meehan M, Bryan K, Watters KM, Murphy DM and Stallings RL: MiRNA-335 suppresses neuroblastoma cell invasiveness by direct targeting of multiple genes from the non-canonical TGF-beta signalling pathway. Carcinogenesis 33 976-985, 2012.

49. Ueno K, Hirata H, Shahryari V, Chen Y, Zaman MS, Singh K, Tabatabai ZL, Hinoda Y and Dahiya R: Tumour suppressor microRNA-584 directly targets oncogene Rock-1 and decreases invasion ability in human clear cell renal cell carcinoma. Br J Cancer 104: 308-315, 2011.

50. Lin SL, Chiang A, Chang D and Ying SY: Loss of mir-146a function in hormone-refractory prostate cancer. RNA 14: 417-424, 2008. 